\title{
A REGULAMENTAÇÃO DA GESTÃo DEMOCRÁTICA E A AÇÃO DO MINISTÉRIO PÚBLICO: DESDOBRAMENTOS NO ESTADO DO RIO DE JANEIRO
}

\author{
LA REGULACIÓN DE LA GESTIÓN DEMOCRÁTICA Y LA ACCIÓN DEL \\ MINISTERIO PÚBLICO: DESARROLLOS EN EL ESTADO DE RÍO DE \\ JANEIRO
}

THE REGULATION OF DEMOCRATIC MANAGEMENT AND THE ROLE OF THE PUBLIC MINISTRY: ACTIONS IN THE STATE OF RIO DE JANEIRO

\author{
Daniela Patti do AMARAL ${ }^{1}$
}

RESUMO: O artigo tem como objetivo explicitar ações do Ministério Público (MP) do estado do Rio de Janeiro junto aos municípios acerca da regulamentação da gestão democrática nas legislações com foco no provimento da direção de escolas públicas. Em levantamento realizado no site do Ministério Público do estado do Rio de Janeiro nos meses de março a setembro de 2017 identificamos ações do MP estadual direcionadas a 26 municípios. Simultaneamente, realizamos buscas nos sites da Câmara de Vereadores, Secretarias de Educação e Prefeituras desses municípios na tentativa de identificar legislações sobre a regulamentação da gestão democrática e do processo de seleção de diretores que tenham sido sancionadas após a aprovação dos respectivos planos municipais de educação. Localizamos legislações e notícias que contemplam o processo de seleção de diretores, no entanto a maior parte dos municípios não regulamentou a gestão democrática em suas redes de educação ou não disponibilizaram publicamente legislação pertinente. A atuação do MP estadual do Rio de Janeiro tem se mostrado presente na busca da regulamentação da gestão democrática apesar da pouca ação concreta dos municípios. No entanto, mesmo após a regulamentação o processo de seleção de diretores ainda demonstra a fragilidade da democracia da educação pública. Como desdobramento da pesquisa, sugerimos o acompanhamento permanente dos processos de regulamentação da gestão democrática e do processo de seleção e diretores.

PALAVRAS-CHAVE: Planos Municipais de Educação. Ministério Público Estadual. Gestão democrática. Diretores escolares.

RESUMEN: El artículo tiene como objetivo explicitar acciones del Ministerio Público (MP) del estado de Río de Janeiro junto a los municipios acerca de la reglamentación de la gestión democrática en las legislaciones con foco en la provisión de la dirección de escuelas públicas. En un estudio realizado en el sitio del Ministerio Público del estado de Río de Janeiro en los meses de marzo a septiembre de 2017 identificamos

${ }^{1}$ Universidade Federal do Rio de Janeiro (Ufrj), Rio de Janeiro - RJ - Brasil. Professora Associada da Faculdade de Educação e do Programa de Pós-Graduação em Educação. E-mail: danielapatti.ufrj@gmail.com. 
acciones del MP estadual dirigidas a 26 municipios. Simultáneamente, realizamos búsquedas en los sitios de la Cámara de los Concejales, Secretarias de Educación y Ayuntamientos de esos municipios en el intento de identificar legislaciones sobre la reglamentación de la gestión democrática y del proceso de selección de directores que hayan sido sancionadas después de la aprobación de los respectivos planes municipales de educación. En el caso de la mayoría de los municipios no ha regulado la gestión democrática en sus redes de educación o no ha puesto públicamente legislación pertinente. La actuación del MP estatal de Río de Janeiro se ha mostrado presente en la búsqueda de la reglamentación de la gestión democrática a pesar de la poca acción concreta de los municipios. Sin embargo, incluso después de la reglamentación, el proceso de selección de directores todavía demuestra la fragilidad de la democracia de la educación pública. Como desdoblamiento de la investigación, sugerimos el acompañamiento permanente de los procesos de regulación de la gestión democrática y del proceso de selección y directores.

PALABRAS CLAVE: Planes Municipales de Educación. Ministerio Público del Estado. Gestión democrática. Diretores escolares.

ABSTRACT: The purpose of this article is to explain the actions of the Public Ministry (MP) of the state of Rio de Janeiro with the municipalities about the regulation of democratic management in the legislations focused on the provision of public school management. In a survey conducted on the website of the Public Ministry of the state of Rio de Janeiro from March to September 2017, we identified actions of the state MP addressed to 26 municipalities. At the same time, we searched the Websites of the City Council, Education Secretaries and City Halls of these municipalities in an attempt to identify legislation on the regulation of democratic management and the selection process of public school director have been sanctioned after the approval of the respective municipal education plans. We have found legislation and news covering the selection process for directors, but most municipalities have not regulated democratic management in their education networks or have not publicly made relevant legislation publicly available. The performance of the state MP of Rio de Janeiro has been present in the search for the regulation of democratic management despite the little concrete action of the municipalities. However, even after regulation, the selection process of directors still demonstrates the fragility of public education democracy. As a result of the research, we suggest the permanent monitoring of the processes of regulation of democratic management and the selection process and directors.

KEYWORDS: Municipal Education Plans. State Public Ministry. Democratic management. School principals.

\section{Introdução}

Os pressupostos teóricos do presente artigo estão embasados na perspectiva de que a eleição de diretores de escolas públicas é um dos critérios fundamentais para a consolidação de uma gestão democrática. Como afirmado por Souza (2009, p. 125), a

RPGE - Revista on line de Política e Gestão Educacional, Araraquara, v. 22, n. esp.1, p. 9-30, mar., 2018. 
gestão democrática deve ser entendida "como um processo político no qual as pessoas que atuam na/sobre a escola identificam problemas, discutem, deliberam e planejam, encaminham, acompanham, controlam e avaliam o conjunto das ações voltadas ao desenvolvimento da própria escola na busca da solução daqueles problemas". Um processo que, segundo o autor, tem como base a participação efetiva de todos os segmentos da comunidade escolar, o respeito às normas coletivamente construídas para os processos de tomada de decisões e, ainda, a garantia de amplo acesso às informações aos sujeitos da escola.

No que diz respeito ao provimento da direção de escolas, dados do INEP (2016) apontam que $45,5 \%$ dos diretores que atuam na gestão das escolas públicas no país foram indicados e apenas $21 \%$ foram eleitos. Os que chegaram via concurso público somam 7,6\%, 3,3\% foram submetidos a algum processo seletivo; $5,2 \%$ por processo seletivo somado à indicação; $5,2 \%$ através de outras formas e 12,2\% através de processo seletivo e eleição. Conforme Lima (2014), pesquisas realizadas ao longo das últimas três décadas no contexto das escolas portuguesas permitiram o estabelecimento de uma forte associação teórica entre gestão democrática e eleição, colegialidade, participação na decisão. Conforme o autor são três dimensões consideradas cruciais, certamente associadas a outras também relevantes, mas, em todo o caso, dependentes daquelas ou a elas subordinadas.

O artigo 206 da Constituição Federal (BRASIL, 1988) estabeleceu que o ensino será ministrado com base em diferentes princípios e, dentre eles, a gestão democrática na forma da lei e, também, de leis complementares. A LDB 9.394 (BRASIL, 1996) em seu artigo $3^{\circ}$, inciso VIII, retomou o debate acerca da gestão democrática apresentado no texto Constitucional na tentativa de deixá-lo menos abrangente. Entretanto, conforme a referida LDB, a gestão democrática do ensino público ocorrerá na forma desta Lei e da legislação dos sistemas de ensino dando destaque para a necessidade dos entes federados regulamentarem suas normas para implementação da gestão democrática, com base em suas particularidades, em consonância com a legislação nacional. Em 2014, foi aprovado o Plano Nacional de Educação (BRASIL, 2014) com 14 artigos e 20 metas acompanhadas de diversas estratégias. O artigo $9^{\circ}$ do PNE estabeleceu que os entes federados deverão aprovar, no prazo de dois anos a partir da publicação do Plano, leis específicas que promovam e disciplinem a gestão democrática da educação pública para os seus sistemas de ensino. A meta 19 do PNE prevê

assegurar condições, no prazo de 2 (dois) anos, para a efetivação da gestão democrática da educação, associada a critérios técnicos de mérito e desempenho e à consulta pública à comunidade escolar, no

RPGE - Revista on line de Política e Gestão Educacional, Araraquara, v. 22, n. esp.1, p. 9-30, mar., 2018. 
âmbito das escolas públicas, prevendo recursos e apoio técnico da União para tanto

A estratégia 19.1 determina

priorizar o repasse de transferências voluntárias da União na área da educação para os entes federados que tenham aprovado legislação específica que regulamente a matéria na área de sua abrangência, respeitando-se a legislação nacional, e que considere, conjuntamente, para a nomeação dos diretores e diretoras de escola, critérios técnicos de mérito e desempenho, bem como a participação da comunidade escolar.

No caso dos demais entes federados, espera-se que a elaboração e aprovação dos planos de educação ocorram por meio de diferentes percursos em contextos diversos, conforme o movimento político de cada estado ou município que inclui: a realização ou não de audiências públicas, consultas à comunidade, a atuação do corpo técnico do poder executivo e a composição do poder legislativo. Destacamos, entretanto, que nem sempre a legislação local está alinhada à legislação nacional. Lima (1998) afirma que a produção de uma regra não garante, obrigatoriamente e automaticamente a sua reprodução por parte de quem age e toma decisões. Segundo o autor (2011), por vezes, podem constituir bons indicadores das dificuldades ou incapacidades de resolver problemas e de concretizar mudanças decretadas, procurando compensar o déficit de mudança através de recursos retóricos e discursos doutrinais ou da reelaboração de certas regras (p. 174). Pode, ainda, demonstrar diferentes graus do que o autor denominou infidelidade normativa.

As influências sofridas no momento da elaboração do PNE resultaram no texto final da Lei e tais influências servem de guia para os estados e municípios visto à necessidade de alinhamento dos planos educacionais às metas e estratégias estabelecidas no PNE. Entretanto, os atores envolvidos no debate e elaboração dos planos no âmbito dos estados e municípios ressignificam e hibridizam, produzindo uma apropriação elástica dos textos da lei nacional a partir de outras perspectivas na consolidação das suas legislações próprias. No contexto da aprovação dos mecanismos que irão assegurar a gestão democrática nas escolas públicas, os poderes executivo e legislativo têm papel fundamental na sanção da legislação que irá materializar questões que abarcam a gestão democrática tais como o processo de seleção de diretores de escolas, composição dos conselhos escolares e grêmios dos estudantes, associação de pais e responsáveis, dentre outros aspectos.

RPGE - Revista on line de Política e Gestão Educacional, Araraquara, v. 22, n. esp.1, p. 9-30, mar., 2018. 
Tendo em vista que a aprovação da quase totalidade dos planos de educação dos municípios do estado do Rio de Janeiro ocorreu em $2015^{2}$, o prazo para aprovação da legislação que regulamente a gestão democrática já expirou. Nesse contexto, observamos que o Ministério Público (MP) do estado do Rio de Janeiro tem enviado recomendações a diferentes municípios exigindo a regulamentação. Face ao exposto, o presente artigo tem como objetivo explicitar algumas ações do MP acerca da regulamentação da gestão democrática nas legislações municipais e os encaminhamentos por parte de alguns municípios dos processos de seleção dos diretores das escolas públicas no bojo de uma gestão democrática da educação pública municipal. Não estamos aqui afirmando que a regulamentação é efeito direto ou resultado exclusivo da ação do MP, mas acreditamos que as Recomendações, a Ação Civil Pública e os Inquéritos são ações que podem gerar ações em âmbito municipal.

O Ministério Público, no Brasil, é configurado como instituição autônoma e independente que não está subordinada aos Poderes Executivo, Legislativo ou Judiciário. A finalidade de sua existência, conforme o texto Constitucional é a defesa da ordem jurídica, do regime democrático e dos interesses sociais e individuais indisponíveis, isto é, a função de defesa da sociedade no regime democrático instituído pela Constituição de 1988, tendo sua atuação comprometida com a defesa da cidadania e da dignidade da pessoa humana. Silveira (2010, p. 240) destaca que o MP assumiu uma função de zelar pelos direitos e garantias legais, atuando administrativa e/ou judicialmente. Conforme a autora, no caso da educação, a sociedade pode fazer valer os seus direitos contra os abusos ou omissões do Estado por meio de instrumentos processuais como o Mandado de Segurança, o Mandado de Injunção e a Ação Civil Pública. O MP pode fazê-lo pela via extrajudicial, utilizando-se de Inquérito Civil, Procedimento Administrativo e Sindicância. Segundo Silveira (2010), no processo de investigação do descumprimento dos direitos e garantias legais, o MP pode requisitar informações por meio de notificações, bem como exigir exames, perícias e documentos, além de promover inspeções às instituições públicas e privadas.

No campo educacional, o Ministério Público do estado do Rio de Janeiro tem papel na fiscalização da qualidade do serviço ofertado pelos sistemas de ensino em todas as etapas da educação básica. São expedidas recomendações, celebrados termos

${ }^{2}$ Dentre os 92 municípios que compõem o estado do Rio de Janeiro, 90 aprovaram seus Planos em 2015 e um em 2017 (Volta Redonda). O município do Rio de Janeiro, até o momento de conclusão deste texto, não havia aprovado seu Plano de Educação. 
de ajustamento de conduta ou distribuídas ações civis públicas para regularização como, por exemplo, da inexistência de plano de educação no município ou no estado, do descumprimento das metas dos planos existentes, da ausência de regime colaborativo entre os entes da federação, da insuficiência do número de vagas oferecidas na rede pública, do princípio da gestão democrática das escolas públicas, entre outros.

Em agosto de 2014, o MP do estado do Rio de Janeiro publicou um documento denominado "Cartilha Controle Social na Educação - Gestão Democrática e Conselhos" (MINISTÉRIO PÚBLICO DO ESTADO DO RIO DE JANEIRO, 2014, pp.9-10). Conforme o documento,

para o efetivo aprendizado do exercício da cidadania nas escolas se faz necessário que a gestão destas seja democrática [..]. É criar e manter espaços de diálogo e de construção conjunta nas escolas, para que se possa conferir prioridade ao que a própria comunidade escolar de fato escolheu ser prioritário [..] conferir democracia à gestão é colocá-la a serviço da coletividade.

Em relação à meta 19 do PNE (BRASIL, 2014), o documento do Ministério Público afirma que, para a plena realização do princípio da gestão democrática do ensino não basta assegurar que as direções das unidades sejam escolhidas pela comunidade escolar, mas também que deverá ser assegurado o real e autônomo funcionamento dos conselhos legalmente previstos para a área da educação, especialmente os escolares. Nesse aspecto, a perspectiva do MP se aproxima das ponderações de Lima (2014) quando o autor afirma que a eleição, do ponto de vista democrático, é uma opção mais coerente para as escolas públicas e "mais favorável à possível combinação entre práticas de democracia direta e práticas de democracia representativas nas escolas" (p. 1071). Mas, só a direção isolada, mesmo que eleita, não garante a construção e consolidação da gestão democrática. A demanda deve ser pela participação e pela colegialidade. Como destacado por Lima (2014), "só o poder de decidir confere pleno sentido às práticas de governo democrático das escolas, rompendo com encenações participativas, com rituais, processos e métodos formalmente democráticos, mas a que falta substantividade democrática” (p. 1072).

Para a elaboração do presente artigo nosso percurso metodológico pautou-se pela busca no endereço eletrônico do Ministério Público do estado do Rio de Janeiro, no período compreendido entre os meses de março e agosto de 2017, de documentos exarados pelo MP destinados aos municípios exigindo a regulamentação da gestão democrática e, também, a busca de possíveis efeitos e resultados dessas ações junto aos

RPGE - Revista on line de Política e Gestão Educacional, Araraquara, v. 22, n. esp.1, p. 9-30, mar., 2018. 
municípios. Encontramos orientações do MP destinadas a 26 municípios do estado. Simultaneamente, realizamos nova busca nos endereços eletrônicos das Prefeituras, Secretarias de Educação e Câmaras de Vereadores desses 26 municípios na tentativa de localizar legislações, documentos, portarias e decretos que disciplinem a gestão democrática da educação com foco no processo de seleção dos diretores das escolas públicas municipais conforme determina a meta 19 do PNE (BRASIL, 2O14). Os resultados dessas buscas são explicitados a seguir.

\section{Ações do Ministério Público Estadual (RJ) e a regulamentação da gestão democrática nos municípios}

Os documentos localizados e analisados apontam a exigência do MP em relação à regulamentação da meta 19 do PNE nos municípios e, inclusive, fazem menção ao documento final da CONAE $2010^{3}$ ao determinarem que a gestão democrática precisa ser assumida como fator de melhoria da qualidade da educação. O Ministério Público reforça a ideia de que a efetivação da gestão democrática não se restringe à forma de escolha das direções das unidades pela comunidade escolar, embora este seja um fator de grande relevância. Os documentos destacam que o princípio Constitucional da gestão democrática engloba o funcionamento de fóruns permanentes de educação, grêmios estudantis, associações de pais e o funcionamento autônomo dos conselhos legalmente previstos. Os documentos instam os municípios - tanto o poder executivo como o legislativo - acerca de informações quanto à existência de projeto de lei em tramitação que discipline a gestão democrática bem como o cronograma dos debates com a sociedade para elaboração e aprovação da lei. Destaco que o MP assume a perspectiva de "legislação específica" contida na estratégia 19.1 do PNE se materializa através de um projeto de lei.

Para ilustrar o movimento da regulamentação da gestão democrática nos municípios do estado do Rio de Janeiro apresentamos no quadro 1 as metas e estratégias presentes nos planos de educação dos municípios que foram alvo de ações do MP. Adicionalmente, incluímos trechos dos documentos encaminhados pelo MP estadual

3 A Conferência Nacional de Educação - CONAE ocorreu em abril de 2010 e tematizou a educação escolar, da Educação Infantil à Pós-Graduação. O Tema da CONAE, definido por sua Comissão Organizadora Nacional, foi: Construindo um Sistema Nacional Articulado de Educação: Plano Nacional de Educação, suas Diretrizes e Estratégias de Ação.

RPGE - Revista on line de Política e Gestão Educacional, Araraquara, v. 22, n. esp.1, p. 9-30, mar., 2018. 
aos municípios que versassem sobre a regulamentação da gestão democrática após a aprovação dos planos municipais de educação. Em vista às limitações do presente artigo, nossa análise recairá sobre os processos de seleção dos diretores das escolas públicas por entendermos que é um dos mecanismos, dentre outros, que compõem o processo de consolidação da gestão democrática das escolas públicas.

Quadro 1: Planos Municipais

\begin{tabular}{|c|c|c|}
\hline MUNICÍPIO & DOCUMENTO DO MP & $\begin{array}{l}\text { META/ESTRATÉGIA DO PME E O } \\
\text { PROCESSO DE SELEÇÃO DOS } \\
\text { DIRETORES }\end{array}$ \\
\hline Volta Redonda & $\begin{array}{l}\text { Portaria de Instauração de inquérito } \\
\text { civil n. } 2 / 17 \text { de } 12 / 1 / 2017 \text {. Fiscalizar } \\
\text { a adequação da legislação específica } \\
\text { que disciplina a gestão democrática } \\
\text { da educação pública no sistema } \\
\text { municipal de ensino aos termos } \\
\text { previstos no PNE. }\end{array}$ & $\begin{array}{l}\text { PME - Lei 5.345/2017 } \\
\text { Estratégia 19.20. Formular no prazo de dois } \\
\text { anos, a partir da implantação de um grupo de } \\
\text { estudos, um novo regimento eleitoral com } \\
\text { especial atenção a limitação da reeleição da } \\
\text { equipe diretiva. }\end{array}$ \\
\hline Vassouras & $\begin{array}{l}\text { Portaria de Instauração de inquérito } \\
\text { civil n. } 20 / 2016 \text { de } 26 / 2 / 2016 . \\
\text { Acompanhar as providências } \\
\text { adotadas pelo município de Vassouras } \\
\text { para elaboração e aprovação de lei } \\
\text { específica que discipline a gestão } \\
\text { democrática da educação pública. } \\
\text { Recomendação n. } 2 / 17 \text { recomenda a } \\
\text { adoção de providências pertinentes } \\
\text { para a edição de legislação específica } \\
\text { que assegure o processo de eleição } \\
\text { direta para diretores das unidades } \\
\text { escolares com observância de } \\
\text { critérios técnicos de mérito e } \\
\text { desempenho. } \\
\text { Recomendação n.2/17 de } 6 \text { de março } \\
\text { de } 2017 \text {. Que recomenda ao Prefeito } \\
\text { que adote as providências pertinentes } \\
\text { para a edição de legislação específica } \\
\text { que assegure o processo de eleição } \\
\text { direta para diretores das unidades } \\
\text { escolares. }\end{array}$ & $\begin{array}{l}\text { PME - Lei 2.820/2015 } \\
\text { Meta } 19 \text { - Implantar eleição democrática para } \\
\text { cargos de Direção em consonância com a Lei } \\
\text { Municipal No } 2.744 / 2014 \text {, para a efetivação } \\
\text { da Gestão Democrática da Educação, no } \\
\text { âmbito das Escolas Municipais. } \\
\text { Estratégia } 19.6 \text { - Realizar a eleição para o } \\
\text { cargo de diretor das escolas municipais a } \\
\text { partir da aprovação deste Plano conforme } \\
\text { prevê a Lei Municipal no } 2.744 / 2014 \text {. }\end{array}$ \\
\hline Três Rios & $\begin{array}{l}\text { Portaria de Instauração de inquérito } \\
\text { civil público N. } 4 / 2017 \text { de } 6 \text { de } \\
\text { fevereiro de } 2017 \text {. Acompanhar as } \\
\text { providências adotadas pelo Município } \\
\text { de Três Rios para o cumprimento da } \\
\text { meta } 19 \text { referente à efetivação da } \\
\text { gestão democrática da educação } \\
\text { associada a critérios técnicos de } \\
\text { mérito e desempenho e à consulta } \\
\text { pública à comunidade escolar, no } \\
\text { âmbito das escolas públicas, prevendo } \\
\text { apoio técnico da União para tanto. }\end{array}$ & $\begin{array}{l}\text { PME - Lei 4.208/2015 } \\
\text { Meta 19: Organizar legislação municipal } \\
\text { específica que regulamente a matéria na área } \\
\text { de sua abrangência, respeitando-se a } \\
\text { legislação nacional, até o segundo ano deste } \\
\text { plano e que considere, conjuntamente, para a } \\
\text { nomeação dos diretores de escola, critérios } \\
\text { técnicos de mérito e desempenho, bem como } \\
\text { a participação da comunidade escolar. }\end{array}$ \\
\hline Sumidouro & $\begin{array}{l}\text { Portaria n. 7/2016 de } 15 \text { de março de } \\
2016 \text { da Promotoria de Justiça da }\end{array}$ & $\begin{array}{l}\text { PME - Lei 1.116/2015 } \\
\text { Estratégia 19.1- Instituir a eleição direta para }\end{array}$ \\
\hline
\end{tabular}

RPGE - Revista on line de Política e Gestão Educacional, Araraquara, v. 22, n. esp.1, p. 9-30, mar., 2018. 


\begin{tabular}{|c|c|c|}
\hline & $\begin{array}{l}\text { Comarca de Sumidouro. Acompanhar } \\
\text { as providências adotadas pelo } \\
\text { Município de Sumidouro para } \\
\text { elaboração e aprovação de lei } \\
\text { específica que discipline a gestão } \\
\text { democrática da educação pública. }\end{array}$ & $\begin{array}{l}\text { o cargo de gestor, nas escolas públicas } \\
\text { municipais. }\end{array}$ \\
\hline $\begin{array}{l}\text { São Pedro da } \\
\text { Aldeia }\end{array}$ & $\begin{array}{l}\text { Portaria de Instauração de inquérito } \\
\text { civil público n. } 3 / 2016 \text {. Acompanhar } \\
\text { as providências adotadas pelo } \\
\text { município de São Pedro da Aldeia } \\
\text { para elaboração e aprovação de lei } \\
\text { específica que discipline a gestão } \\
\text { democrática da educação pública. }\end{array}$ & $\begin{array}{l}\text { PME - Lei } 2.606 / 2015 \\
\text { Estratégia } 19.9 \text { - Regulamentar as condições } \\
\text { para efetivação da gestão por mérito e } \\
\text { consulta à comunidade escolar da rede } \\
\text { municipal de ensino, no prazo de } 12 \text { (doze) } \\
\text { meses a partir da aprovação deste Plano. }\end{array}$ \\
\hline Saquarema & $\begin{array}{l}\text { Portaria de Instauração de inquérito } \\
\text { civil público n. } 2 / 2016 \text { de } 16 / 2 / 2016 \text {. } \\
\text { Acompanhar as providências } \\
\text { adotadas pelo município de } \\
\text { Saquarema para elaboração e } \\
\text { aprovação de lei específica que } \\
\text { discipline a gestão democrática da } \\
\text { educação pública. }\end{array}$ & $\begin{array}{l}\text { PME - Lei } 1.427 / 2015 \\
\text { Estratégia } 19.12 \text { - desenvolver programas de } \\
\text { formação de diretores e gestores escolares, } \\
\text { bem como aplicar prova nacional específica, } \\
\text { a fim de subsidiar a definição de critérios } \\
\text { objetivos para o provimento dos cargos, } \\
\text { cujos resultados possam ser utilizados por } \\
\text { adesão, bem como garantir o padrão de } \\
\text { qualidade de ensino. }\end{array}$ \\
\hline Sapucaia & $\begin{array}{l}\text { Portaria de Instauração de inquérito } \\
\text { civil público s/n de } 14 \text { de julho de } \\
\text { 2016. A portaria não menciona } \\
\text { especificamente a regulamentação da } \\
\text { gestão democrática, mas que o } \\
\text { município informe as estratégias } \\
\text { adotadas pelo poder executivo para } \\
\text { dar efetividade às metas estabelecidas } \\
\text { no PME. }\end{array}$ & $\begin{array}{l}\text { PME - Lei 2.593/2015 } \\
\text { Estratégia 19.15) Sugerir, a partir desse } \\
\text { plano, que haja um processo eleitoral para } \\
\text { equipe diretiva com a participação da } \\
\text { comunidade escolar, havendo data prevista } \\
\text { para que os candidatos elaborem e } \\
\text { apresentem um plano de gestão para o } \\
\text { exercício no período de 2(dois) anos, } \\
\text { podendo haver reeleição. }\end{array}$ \\
\hline Rio Claro & $\begin{array}{l}\text { Portaria de Instauração de inquérito } \\
\text { civil público N. } 4 / 2016 \text { de } 15 \text { de abril } \\
\text { de } 2016 \text {. Acompanhar as providências } \\
\text { adotadas pelo município de Rio Claro } \\
\text { para elaboração e aprovação de lei } \\
\text { específica que discipline a gestão } \\
\text { democrática da educação pública. }\end{array}$ & $\begin{array}{l}\text { PME - Lei } 792 / 2015 \\
\text { Estratégia } 19.6 \text { - Garantir que os gestores } \\
\text { escolares fossem eleitos através da } \\
\text { Comunidade Escolar com Gestão de } 2 \text { anos, } \\
\text { podendo ser reeleitos. }\end{array}$ \\
\hline Paraíba do Sul & $\begin{array}{l}\text { Portaria de Instauração de inquérito } \\
\text { civil público N. } 3 / 2017 \text { de } 3 \text { de março } \\
\text { de } 2017 \text {. Acompanhar as providências } \\
\text { adotadas pelo município de Paraíba } \\
\text { do Sul para elaboração e aprovação } \\
\text { de lei específica que discipline a } \\
\text { gestão democrática da educação } \\
\text { pública. }\end{array}$ & $\begin{array}{l}\text { PME - Lei 3.187/2015 } \\
\text { 3.10.2 - Diretrizes e Metas: Estabelecer } \\
\text { normas para eleger através de concurso } \\
\text { interno e ou processo seletivo de gestores das } \\
\text { Unidades Escolares de Ensino da Rede } \\
\text { Municipal de Paraíba do Sul. }\end{array}$ \\
\hline Nova Friburgo & $\begin{array}{l}\text { Portaria de Instauração de inquérito } \\
\text { civil público N. 24/2016 de } 4 \text { de } \\
\text { agosto de 2016. Acompanhar as } \\
\text { providências adotadas pelo município } \\
\text { de Nova Friburgo para elaboração e } \\
\text { aprovação de lei específica que } \\
\text { discipline a gestão democrática da } \\
\text { educação pública. }\end{array}$ & $\begin{array}{l}\text { PME - Lei } 4.395 / 2015 \\
\text { 13. Garantir o processo de escolha } \\
\text { democrática, com conceito de eleição } \\
\text { circunscrita de diretor e dirigentes de } \\
\text { unidades escolares, respeitados os critérios } \\
\text { estabelecidos pelo Conselho Municipal de } \\
\text { Educação, com mandato de } 2 \text { anos, com } \\
\text { direito a uma reeleição. }\end{array}$ \\
\hline Natividade & $\begin{array}{l}\text { Portaria de Instauração de inquérito } \\
\text { civil público N. 14/2016 de } 3 \text { de } \\
\text { junho de 2016. Acompanhar as } \\
\text { providências adotadas pelo município } \\
\text { de Natividade para elaboração e } \\
\text { aprovação de lei específica que }\end{array}$ & $\begin{array}{l}\text { PME - Lei. 726/2015 } \\
\text { Estratégias } \\
\text { 19.1) Instituir Lei Municipal que define } \\
\text { critérios de participação da comunidade } \\
\text { escolar na eleição de diretores de escolas e } \\
\text { Creches. }\end{array}$ \\
\hline
\end{tabular}

RPGE - Revista on line de Política e Gestão Educacional, Araraquara, v. 22, n. esp.1, p. 9-30, mar., 2018. 


\begin{tabular}{|c|c|c|}
\hline & $\begin{array}{l}\text { discipline a gestão democrática da } \\
\text { educação pública. }\end{array}$ & $\begin{array}{l}\text { 19.2) Instituir Lei Municipal para eleição de } \\
\text { Diretores de Escolas e Creches, mediante } \\
\text { critérios técnicos de mérito e desempenho, } \\
\text { considerados preferencialmente pedagogos, } \\
\text { seguidos de graduados em licenciaturas, } \\
\text { desde que membros efetivos do magistério } \\
\text { Público Municipal. }\end{array}$ \\
\hline Iguaba Grande & $\begin{array}{l}\text { Portaria de Instauração de inquérito } \\
\text { civil público N. } 2 / 2016 \text { de } 5 \text { de } \\
\text { fevereiro de } 2016 \text {. Acompanhar as } \\
\text { providências adotadas pelo município } \\
\text { de Iguaba Grande para elaboração e } \\
\text { aprovação de lei específica que } \\
\text { discipline a gestão democrática da } \\
\text { educação pública }\end{array}$ & $\begin{array}{l}\text { PME - Lei 1.174/2015 } \\
\text { Estratégia 19.7- Desenvolver programas de } \\
\text { formação de gestores, candidatos ao cargo, } \\
\text { estabelecendo consulta para a troca de } \\
\text { direção a cada } 2 \text { anos, garantindo formação } \\
\text { para os candidatos a partir do } 1^{\circ} \text { semestre de } \\
2016 \text {, para início do processo de consulta } \\
\text { iniciando a Gestão democrática em } 2017 \text {. }\end{array}$ \\
\hline Laje do Muriaé & $\begin{array}{l}\text { Recomendação Administrativa N. } \\
\text { 1/2016. Portaria de Instauração de } \\
\text { inquérito civil público N. 4/2016 de } \\
25 \text { de abril de } 2016 \text {. Acompanhar as } \\
\text { providências adotadas pelo município } \\
\text { de Laje do Muriaé para elaboração e } \\
\text { aprovação de lei específica que } \\
\text { discipline a gestão democrática da } \\
\text { educação pública. }\end{array}$ & $\begin{array}{l}\text { PME - Lei 736/2015 } \\
\text { Meta 18: } \\
\text { Garantir, em leis específicas aprovadas no } \\
\text { âmbito Municipal, a efetivação da gestão } \\
\text { democrática na educação básica e informada } \\
\text { pela prevalência de decisões colegiadas nos } \\
\text { órgãos dos sistemas de ensino e nas } \\
\text { instituições de educação, e forma de acesso } \\
\text { às funções de direção que conjuguem mérito } \\
\text { e desempenho à participação das } \\
\text { comunidades escolares. }\end{array}$ \\
\hline $\begin{array}{lll}\text { São José de } & \text { dó } \\
\text { Ubá } & & \end{array}$ & $\begin{array}{l}\text { Portaria de Instauração de inquérito } \\
\text { civil público N. 2/2016 de } 19 \text { de } \\
\text { fevereiro de } 2016 \text {. Acompanhar as } \\
\text { providências adotadas pelo município } \\
\text { de São José do Ubá para elaboração e } \\
\text { aprovação de lei específica que } \\
\text { discipline a gestão democrática da } \\
\text { educação pública. }\end{array}$ & $\begin{array}{l}\text { PME - Lei 427/2015 } \\
\text { Estratégias - Garantir no prazo de } 2 \text { (dois) } \\
\text { anos a partir da aprovação deste PME, o } \\
\text { processo de legitimação da direção das } \\
\text { unidades educativas da rede municipal de } \\
\text { ensino considerando para a nomeação dos } \\
\text { diretores e diretoras de escola critérios } \\
\text { técnicos de mérito e desempenho, bem como } \\
\text { a participação da comunidade escolar em } \\
\text { processo eletivo. }\end{array}$ \\
\hline Itaperuna & $\begin{array}{l}\text { Portaria de Instauração de inquérito } \\
\text { civil público N. } 4 / 2016 \text { de } 16 \text { de } \\
\text { março de } 2016 \text {. Acompanhar as } \\
\text { providências adotadas pelo município } \\
\text { de Itaperuna para elaboração e } \\
\text { aprovação de lei específica que } \\
\text { discipline a gestão democrática da } \\
\text { educação pública. }\end{array}$ & $\begin{array}{l}\text { PME - Lei 718/2015 } \\
\text { Estratégia 19.8- Condições para que no prazo } \\
\text { de } 2 \text { (dois) anos, para a efetivação da gestão } \\
\text { democrática da educação, associada a } \\
\text { critérios técnicos de mérito e desempenho e à } \\
\text { consulta pública à comunidade escolar, no } \\
\text { âmbito das escolas públicas, prevendo } \\
\text { recursos e apoio técnico da União para tanto. }\end{array}$ \\
\hline Itaocara & $\begin{array}{l}\text { Portaria de Instauração de inquérito } \\
\text { civil público N. } 8 / 2016 \text { de } 26 \text { de abril } \\
\text { de } 2016 \text {. Acompanhar as providências } \\
\text { adotadas pelo município de Itaocara } \\
\text { para elaboração e aprovação de lei } \\
\text { específica que discipline a gestão } \\
\text { democrática da educação pública. }\end{array}$ & $\begin{array}{l}\text { PME - Lei 1.019/2015 } \\
\text { META } 19 \\
\text { Assegurar condições, no prazo de 06(seis) } \\
\text { meses, para a efetivação da gestão } \\
\text { democrática da educação, no âmbito das } \\
\text { escolas públicas. }\end{array}$ \\
\hline Carmo & $\begin{array}{l}\text { Portaria de Instauração de inquérito } \\
\text { civil público N. 13/2016 de } 1 \text { de abril } \\
\text { de } 2016 \text {. Acompanhar as providências } \\
\text { adotadas pelo município de Carmo } \\
\text { para elaboração e aprovação de lei } \\
\text { específica que discipline a gestão } \\
\text { democrática da educação pública. }\end{array}$ & $\begin{array}{l}\text { PME - Lei 1.763/2015 } \\
\text { Meta 19: } \\
\text { Não menciona }\end{array}$ \\
\hline Rio de Janeiro & $\begin{array}{l}\text { Portaria de Instauração de inquérito } \\
\text { civil público N. } 8 / 2016 \text { de } 31 \text { de }\end{array}$ & $\begin{array}{l}\text { Plano de educação ainda não aprovado. } \\
\text { Resolução SME n. } 20 \text { de 29/9/2017 que }\end{array}$ \\
\hline
\end{tabular}

RPGE - Revista on line de Política e Gestão Educacional, Araraquara, v. 22, n. esp.1, p. 9-30, mar., 2018. 


\begin{tabular}{|c|c|c|}
\hline & $\begin{array}{l}\text { janeiro de } 2016 \text {. Acompanhar as } \\
\text { providências adotadas pelo município } \\
\text { do Rio de Janeiro para o cumprimento } \\
\text { da meta } 19 \text { do PNE. O documento } \\
\text { indaga como ocorre o processo de } \\
\text { escolha para diretor escolar; se a } \\
\text { nomeação dos diretores leva em } \\
\text { consideração critérios técnicos de } \\
\text { mérito e desempenho bem como a } \\
\text { participação da comunidade e se há } \\
\text { legislação municipal específica sobre } \\
\text { o tema. }\end{array}$ & $\begin{array}{l}\text { Dispõe sobre o processo de Seleção de } \\
\text { Gestores das Unidades Escolares da Rede } \\
\text { Pública do Sistema Municipal de Ensino da } \\
\text { Cidade do Rio de Janeiro. Define um } \\
\text { mandato de três anos. Podem se candidatar } \\
\text { os detentores de cargo efetivo de professor } \\
\text { e/ou especialista de educação em atividade e } \\
\text { com origem na Secretaria Municipal de } \\
\text { Educação do Rio de Janeiro que } \\
\text { comprovarem o mínimo de } 5 \text { anos em } \\
\text { regência de turma em unidade escolar na } \\
\text { rede pública municipal de ensino do Rio de } \\
\text { Janeiro ou a permanência por } 3 \text { anos em } \\
\text { cargo comissionado ou função gratificada em } \\
\text { unidade escolar nesta rede. A consulta à } \\
\text { comunidade, que constitui uma das etapas do } \\
\text { processo de seleção de gestores das unidades } \\
\text { escolares, será realizada por meio de } \\
\text { votação. Nos três primeiros meses do } \\
\text { mandato, o ocupante do cargo de Diretor } \\
\text { deverá coordenar o processo de construção } \\
\text { de um projeto de gestão, em conjunto com a } \\
\text { comunidade escolar, a ser aprovado pela } \\
\text { Secretaria Municipal de Educação e } \\
\text { implementado na unidade escolar a partir do } \\
\text { ano corrente. }\end{array}$ \\
\hline $\begin{array}{l}\text { Cachoeiras de } \\
\text { Macacu }\end{array}$ & $\begin{array}{l}\text { Inquérito civil público N. } \\
\text { 2016.00724882 de } 1 \text { de julho de } \\
\text { 2016. Acompanhar as providências } \\
\text { adotadas pelo município de } \\
\text { Cachoeiras de Macacu para } \\
\text { elaboração de lei específica que } \\
\text { discipline a gestão democrática da } \\
\text { educação pública. }\end{array}$ & $\begin{array}{l}\text { PME - Lei 2.056/2015 } \\
\text { Meta 19: Assegurar mecanismos, no prazo } \\
\text { de dois anos, para garantir a efetivação da } \\
\text { gestão democrática, nas escolas no âmbito do } \\
\text { município de Cachoeiras de Macacu/RJ. }\end{array}$ \\
\hline Cabo Frio & $\begin{array}{l}\text { Portaria de Instauração de inquérito } \\
\text { civil público N. 14/2016 de } 30 \text { de } \\
\text { abril de 2016. Acompanhar as } \\
\text { providências adotadas pelo município } \\
\text { de Cabo Frio para elaboração de lei } \\
\text { específica que discipline a gestão } \\
\text { democrática da educação pública. }\end{array}$ & $\begin{array}{l}\text { PME - Lei } 2.644 / 2015 \\
\text { 19.9. Assegurar a consulta à comunidade } \\
\text { escolar para escolha das direções das escolas } \\
\text { da Rede Municipal, conforme previsto na } \\
\text { legislação em vigor. }\end{array}$ \\
\hline $\begin{array}{l}\text { Armação de } \\
\text { Búzios }\end{array}$ & $\begin{array}{l}\text { Portaria de Instauração de inquérito } \\
\text { civil público N. } 7 / 2016 \text { de } 21 \text { de } \\
\text { março de } 2016 \text {. Acompanhar as } \\
\text { providências adotadas pelo município } \\
\text { de Armação de Búzios para } \\
\text { elaboração de lei específica que } \\
\text { discipline a gestão democrática da } \\
\text { educação pública. }\end{array}$ & $\begin{array}{l}\text { PME - Lei 1.114/2015 } \\
\text { Meta } 19 \text { - Garantir a consulta pública para a } \\
\text { eleição da equipe diretiva das Unidades } \\
\text { Escolares do município de Armação dos } \\
\text { Búzios. }\end{array}$ \\
\hline Araruama & $\begin{array}{l}\text { Portaria de Instauração de inquérito } \\
\text { civil público N. } 2 / 2016 \text { de } 5 \text { de maio } \\
\text { de } 2016 \text {. Acompanhar as providências } \\
\text { adotadas pelo município de Araruama } \\
\text { para elaboração e aprovação de lei } \\
\text { específica que discipline a gestão } \\
\text { democrática da educação pública. }\end{array}$ & $\begin{array}{l}\text { PME - Lei 1.961/2015 } \\
\text { Estratégia } 8 \text { da meta 19. Estabelecer } \\
\text { critérios, através do Conselho Municipal de } \\
\text { Educação, que definam os requisitos } \\
\text { essenciais a serem analisados na escolha dos } \\
\text { gestores das unidades escolares municipais, } \\
\text { subsidiando, assim, o Executivo Municipal } \\
\text { nessa matéria. }\end{array}$ \\
\hline $\begin{array}{l}\text { Duque } \\
\text { Caxias }\end{array}$ & $\begin{array}{l}\text { Recomendação n. 01/2016 e Ação } \\
\text { Civil Pública por improbidade } \\
\text { Administrativa por omissão do gestor }\end{array}$ & $\begin{array}{l}\text { O PME não apresenta meta específica para a } \\
\text { gestão democrática. O Decreto } 6542 \text { de } \\
11 / 5 / 2015 \text { que dispõe sobre eleições para }\end{array}$ \\
\hline
\end{tabular}

RPGE - Revista on line de Política e Gestão Educacional, Araraquara, v. 22, n. esp.1, p. 9-30, mar., 2018. 


\begin{tabular}{|c|c|c|}
\hline & $\begin{array}{l}\text { municipal no que diz respeito à gestão } \\
\text { democrática }{ }^{4} \text {. Conforme a ação "o réu } \\
\text { quedou-se inerte em sua obrigação } \\
\text { legal de apresentar à Câmara de } \\
\text { Vereadores do Município de Duque } \\
\text { de Caxias projeto de lei que } \\
\text { regulamentasse a gestão democrática } \\
\text { no município". Recomendação } \\
\text { N.16/2017 (Ref: IC 01/2016) de } 29 \text { de } \\
\text { maio de } 2017 \text { recomenda ao Prefeito } \\
\text { do município que no prazo de } 60 \text { dias } \\
\text { promova e organize as discussões } \\
\text { necessárias e indispensáveis em toda } \\
\text { a rede pública municipal de ensino } \\
\text { envolvendo alunos, responsáveis, } \\
\text { professores, servidores e toda a } \\
\text { comunidade interessada para } \\
\text { elaboração de anteprojeto de lei a ser } \\
\text { submetido a análise da Procuradoria- } \\
\text { Geral do município e no prazo de } 20 \\
\text { dias após as necessárias discussões } \\
\text { promova a remessa à Câmara } \\
\text { Municipal de Duque de Caxias } \\
\text { projeto de lei especifica disciplinado } \\
\text { a gestão democrática da educação } \\
\text { pública. }\end{array}$ & $\begin{array}{l}\text { diretores e vice-diretores das unidades } \\
\text { escolares do município de Duque de Caxias. } \\
\text { Conforme o Decreto poderão candidatar-se } \\
\text { todo servidor público municipal d educação } \\
\text { (professores e funcionários) detentor de } \\
\text { cargo de provimento efetivo que esteja em } \\
\text { exercício de suas funções na Rede Municipal } \\
\text { de educação no mínimo } 3 \text { anos com } \\
\text { disponibilidade de } 40 \mathrm{~h} \text { semanais. } \\
\text { Em } 3 / 10 / 2017 \text { foi aprovado o } \\
\text { Projeto de Lei no } 27 / \mathrm{GP} / 2017^{5} \text { que } \\
\text { regulamenta a gestão democrática das } \\
\text { escolas públicas de Duque de Caxias. }\end{array}$ \\
\hline Valença & $\begin{array}{l}\text { Portaria de Instauração de Inquérito } \\
\text { Civil n. } 4 / 16 \text { de } 16 \text { de maio de } 2016 \\
\text { que tem por objetivo “acompanhar as } \\
\text { providências adotadas pelo Município } \\
\text { de Valença para elaboração e } \\
\text { aprovação de lei específica que } \\
\text { discipline a gestão democrática da } \\
\text { educação pública". Determina, entre } \\
\text { outras questões, informação quanto à } \\
\text { existência de projeto de lei em } \\
\text { tramitação sobre o tema. }\end{array}$ & $\begin{array}{l}\text { Meta } 19 \text { do PME Lei } 2865 / 15 \text {. Assegurar } \\
\text { condições, no prazo de } 2 \text { (dois) anos, para a } \\
\text { efetivação da gestão democrática da } \\
\text { educação, no âmbito das escolas públicas. } \\
\text { Resolução da Secretaria 003/2015 de 5/11/2- } \\
15 \text { estabelece normas para eleição de diretor } \\
\text { e diretor adjunto das escolas/creches da rede } \\
\text { municipal de ensino. }\end{array}$ \\
\hline Nilópolis & $\begin{array}{l}\text { Recomendação n. 17/2015 ref. Ao } \\
\text { Inquérito Civil n. 233/2015. } \\
\text { Adequação das metas do PME ao } \\
\text { PNE tendo em vista que a "Meta } 19 \\
\text { do PME não prevê a eleição direta } \\
\text { para a função de Diretor Escolar } \\
\text { dentre as estratégias para } \\
\text { cumprimento da meta" }\end{array}$ & $\begin{array}{l}\text { Lei } 6490 \text { de } 2015 \text {. Meta 19. Assegurar } \\
\text { condições, no prazo de } 2 \text { (dois) anos, para a } \\
\text { efetivação da gestão democrática da } \\
\text { educação, associada a critérios técnicos de } \\
\text { mérito e desempenho e à consulta pública à } \\
\text { comunidade escolar, no âmbito das escolas } \\
\text { públicas, prevendo recursos e apoio técnico } \\
\text { da União para tanto. Uma das estratégias } \\
\text { determina regulamentar em Decreto } \\
\text { Municipal a gestão democrática da educação } \\
\text { pública. }\end{array}$ \\
\hline $\begin{array}{l}\text { Engenheiro } \\
\text { Paulo de } \\
\text { Frontin }\end{array}$ & $\begin{array}{l}\text { Portaria n. 1/2016de 25/7/2016. } \\
\text { Acompanhar as providências } \\
\text { adotadas pelo Município de } \\
\text { Engenheiro Paulo de Frontin para } \\
\text { elaboração e aprovação de lei } \\
\text { específica que disciplina a gestão } \\
\text { democrática da educação pública em } \\
\text { seu sistema de ensino, a fim de } \\
\text { garantir que o prazo estipulado pelo }\end{array}$ & $\begin{array}{l}\text { Lei 1178/15. Art. } 10 \text { - O município de } \\
\text { Engenheiro Paulo de Frontin deverá aprovar } \\
\text { leis específicas disciplinando a gestão } \\
\text { democrática da educação em seus } \\
\text { respectivos âmbitos de atuação. Meta } 19 \text { - } \\
\text { Assegurar condições, no prazo de } 2 \text { (dois) } \\
\text { anos, para a efetivação da gestão } \\
\text { democrática da educação, associada a } \\
\text { critérios técnicos de mérito e desempenho e à }\end{array}$ \\
\hline
\end{tabular}

${ }^{4}$ A Ação Civil Pública foi ajuizada contra o ex-prefeito Alexandre Aguiar Cardoso (mandato 2012-2016).

${ }^{5}$ Não conseguimos acesso ao Projeto de Lei até o momento de finalização deste artigo.

RPGE - Revista on line de Política e Gestão Educacional, Araraquara, v. 22, n. esp.1, p. 9-30, mar., 2018. 


\begin{tabular}{|l|l|l|}
\hline & art. $9^{\circ}$ do PNE seja cumprido. & $\begin{array}{l}\text { consulta pública à comunidade escolar, no } \\
\text { âmbito das escolas públicas, prevendo } \\
\text { recursos e apoio técnico da União para tanto. }\end{array}$ \\
\hline
\end{tabular}

Fonte: Ministério Público do Estado do Rio de Janeiro e Planos Municipais de Educação Adaptado pela autora

Como destacamos anteriormente, na busca realizada nos diferentes endereços eletrônicos dos poderes executivo e legislativo dos municípios investigados, não foram localizadas legislações, documentos, portarias ou quaisquer outras normas que regulamentassem a gestão democrática após a aprovação dos Planos Municipais de Educação nos seguintes municípios: Vassouras, Três Rios, Sapucaia, Rio Claro, São José de Ubá, Laje do Muriaé, Itaperuna, Itaocara, Cachoeiras de Macacu, Armação de Búzios, Araruama, Cabo Frio; Nilópolis; Engenheiro Paulo de Frontin e Paraíba do Sul. Volta Redonda teve o Plano Municipal de Educação sancionado em 30 de maio de 2017, logo, acreditamos que ainda não houve tempo suficiente para a regulamentação da gestão democrática. O município do Rio de Janeiro ainda não teve seu plano de educação sancionado até o momento de finalização do presente artigo, no entanto aprovou uma resolução no dia 29 de setembro que dispõe sobre o processo de seleção dos diretores de escolas públicas.

Sobre o município de Saquarema encontramos uma notícia disponibilizada em uma rede social em $1^{\circ}$ de dezembro de 2016 informando sobre as chapas e candidatos à eleição para diretores das escolas municipais. Mas, após ampla busca de informações em sites oficiais (Prefeitura; Secretaria de Educação e Câmara de vereadores) nenhum documento foi localizado. A dificuldade de encontrar informações disponibilizadas em sites oficiais ilustra a falta de transparência e de atualização para o cidadão e os destinatários das políticas acerca das decisões e ações dos entes públicos.

Em relação ao município de Sumidouro, localizamos a mensagem 008/2016 de 30 de maio de 2016 encaminhada pelo ao presidente da Câmara de Vereadores. Conforme o documento (SUMIDOURO, 2016) é encaminhado à Câmara o Anteprojeto de Lei N. 13 de 24 de maio de 2016 que trata da gestão democrática do ensino público municipal de Sumidouro. O prefeito solicita que seja apreciado em caráter de "urgência especial". Conforme o artigo $3^{\circ}$ "a escolha dos diretores das escolas municipais ocorrerá por meio de seleção mediante critérios de competência técnica e legitimação adicional pela comunidade escolar (eleição)". Adicionalmente, o artigo $9^{\circ}$ determina que "os gestores das escolas públicas municipais serão submetidos ao processo seletivo que constará de provas de competência técnica, eleição e posterior nomeação pelo Poder

RPGE - Revista on line de Política e Gestão Educacional, Araraquara, v. 22, n. esp.1, p. 9-30, mar., 2018. 
Executivo Municipal”. O parágrafo primeiro do artigo $9^{\circ}$ define que, após a publicação da lei, será estabelecido o prazo de 18 meses para adequação do processo de eleição e nomeação de diretores. Não localizamos informações acerca da aprovação da lei.

Conforme noticiado no endereço eletrônico da prefeitura de São Pedro da Aldeia (RODRIGUES, 2017) foi realizada em abril de 2017 consulta pública junto à comunidade para o provimento da direção de escolas públicas em cumprimento à Lei complementar N. 135, de 06 de janeiro de 2017. Conforme noticiado, o processo faz parte do atendimento à meta 19 do Plano Nacional de Educação, que visa, em dois anos, efetivar o processo de consulta às comunidades escolares com as escolhas diretas pelos seus diretores, adjuntos e dirigentes de turno. Os diretores eleitos assumirão a gestão no biênio de 2017-2018. No entanto, não foi localizada a referida lei nem no endereço eletrônico da Prefeitura tampouco no site da Câmara de Vereadores.

Em relação à Nova Friburgo localizamos notícia no site da Prefeitura no dia 2 de fevereiro de 2017 sobre o tema: "educação democrática: diretores eleitos para unidades municipais são empossados em noite emocionante para a comunidade escolar friburguense" (NOVA FRIBURGO, 2017). Ainda conforme a notícia, os diretores foram eleitos democraticamente em novembro de 2016 para mandato de dois anos. Em Nova Friburgo, a Lei Municipal No 3.989 de 01/12/2011 estabelece os critérios para nomeação das direções das instituições de ensino mantidas pelo poder público municipal. No entanto, cabe um destaque: em 5 de julho de 2016 a referida Lei teve seu artigo primeiro alterado pela Lei 4.473/2016. A legislação mais recente define que: “os Diretores e Dirigentes das Instituições de Ensino Municipal mantidas pelo Poder Público, eleitos na forma da legislação anterior, terão o direito à reeleição", sem definir um limite de mandatos. Isto é, permite uma reeleição sem fim, o que pode ser interpretado como um conflito em relação à gestão democrática tendo em vista a permissão de inúmeros mandatos sucessivos se consubstanciando em uma proposta mais patrimonialista do que democrática.

Sobre o município de Natividade foi localizada a Lei municipal 796/2016 que dispõe sobre a gestão democrática do ensino público municipal alinhando-se ao PNE (BRASIL, 2014) e ao PME (NATIVIDADE, 2015). No caso do processo de provimento da direção de escolas, a Lei determina que o diretor e o diretor adjunto serão nomeados pelo Prefeito a partir de eleição pela comunidade escolar.

RPGE - Revista on line de Política e Gestão Educacional, Araraquara, v. 22, n. esp.1, p. 9-30, mar., 2018. 
Em relação ao município de Iguaba Grande, localizamos notícia ${ }^{6}$ no site da Câmara de Vereadores informando que foi aprovado o projeto de Lei N. 16/2016 que dispõe sobre o processo de gestão democrática das escolas da rede municipal e que, até o momento de elaboração do presente artigo, ainda não havia sido sancionado pelo prefeito. Não foi possível obter o texto do Projeto de Lei porque não se encontra disponível nos sites da Prefeitura ou da Câmara de Vereadores.

No município de Carmo foi aprovada a Lei $\mathrm{n}^{\circ}$ 1852/2016, de 25 de novembro de 2016 que "dispõe sobre a instituição da Gestão democrática na rede municipal de ensino de Carmo e dá outras providências". Conforme o artigo $2^{\circ}$ da Lei, "a gestão democrática norteará as ações de planejamento, elaboração, organização, execução e avaliação das políticas educacionais, englobando, dentre outros aspectos, a escolha de diretores de escola, com participação efetiva da comunidade escolar, adotando o sistema eletivo, mediante voto direto e secreto" (CARMO, 2016). Ainda conforme a legislação, “integram a comunidade escolar os alunos, seus pais ou responsáveis e os profissionais de educação lotados nas unidades escolares". Há uma seção destinada à escolha para diretores de escola municipal. Conforme o artigo 15, "os critérios para escolha de diretores têm como referência clara os campos do conhecimento, da competência e liderança, na perspectiva de assegurar um conhecimento da realidade onde se insere" (CARMO, 2016).

Duque de Caxias, Valença e Rio de Janeiro são os municípios nos quais localizamos legislação que regulamentou o processo de seleção dos diretores de escola. Não podemos afirmar que a atuação do MP tenha provocado ações nos municípios, o que demandaria uma investigação mais apurada, no entanto, acreditamos que o MP é um ator importante nesse cenário e sua ação gera efeitos e resultados nos municípios.

Duque de Caxias regulamentou a gestão democrática, inicialmente, através do Decreto n. 6542 de 11 de maio de 2015. Em 3 de outubro de 2017 foi aprovado pela Câmara dos Vereadores o Projeto de Lei no 27/GP/2017 que regulamenta a gestão democrática das escolas públicas de município.

No município de Valença a eleição de diretor e diretor adjunto das escolas e creches da rede municipal foi regulamentada através da Resolução n. 3/2015 da Secretaria Municipal de Educação de 3 de novembro de 2015. O Rio de Janeiro ainda não teve seu plano de educação sancionado, no entanto, a Secretaria de Educação

6 Disponível em: <http://iguabagrande.rj.leg.br/institucional/noticias/vereadores-participam-de-forummunicipal-de-educacao-em-iguaba-grande>. Acesso em: 25 jun. 2017.

RPGE - Revista on line de Política e Gestão Educacional, Araraquara, v. 22, n. esp.1, p. 9-30, mar., 2018. 
aprovou em 29 de setembro de 2017 a resolução N. 3 que dispõe sobe o processo seletivo dos diretores e diretores adjuntos das escolas públicas. Ponderamos que a utilização da estratégia de regulamentação via decreto e resolução e não projeto de lei apresenta sérias implicações para a democracia tendo em vista que, tanto um decreto como uma resolução podem ser revogados a qualquer momento, dando fragilidade ao processo já que não foi objeto de negociação, debate e audiências públicas no legislativo. Importante lembrar que os documentos exarados pelo MP, como anteriormente destacado, definem o projeto de lei como legislação específica na regulamentação do processo de seleção de diretores. Mais uma vez, ressaltamos a fragilidade legal de uma resolução e um decreto sem o valor e o capital simbólico de uma lei aprovada após amplo debate com a sociedade. Compreendemos que, mesmo após regulamentação nesses municípios, a gestão democrática e o processo de seleção de diretores de escola pública ainda se encontram em terreno frágil e movediço.

\section{Considerações finais}

Observa-se que a regulamentação da gestão democrática parece ter resultado em ações em alguns municípios: Carmo aprovou legislação; Iguaba Grande aprovou Projeto de Lei que aguarda sanção do prefeito; Saquarema realizou eleições para diretores; Sumidouro tem anteprojeto enviado à Câmara pelo Executivo; em São Pedro da Aldeia a consulta à comunidade foi realizada; Natividade regulamentou o processo de seleção dos diretores; Nova Friburgo já promovia a eleição, mas enfrenta uma nova questão acerca do tempo do mandato; Duque de Caxias aprovou um Decreto e uma Lei e Valença e o Rio de Janeiro aprovaram resoluções. No entanto, outros 18 municípios ainda não atenderam às determinações do PNE (BRASIL, 2014) e exigências do MP. Destacamos que o uso do termo "legislação específica" na estratégia 19.1 do PNE foi utilizado em atenção à autonomia dos demais entes federados. Afinal, tanto uma lei, como um decreto e uma resolução se enquadram na categoria de "legislação específica". A questão é: usando uma régua para mensurar as estratégias políticas utilizadas, qual a escala de democracia de cada modelo documental escolhido pelo município para a regulamentação?

As ações do MP estadual são relevantes na perspectiva do cumprimento do que foi regulamentado pelo PNE e, ainda, para assegurar o fim dos traços patrimonialistas do país no que diz respeito ao provimento da direção de escolas públicas. O 
patrimonialismo, conforme salienta Shwartzman (2003) permanece em seus traços socioculturais ao longo da história da administração pública brasileira, apenas assumindo atualmente outras configurações e nuances.

Face ao exposto, na prerrogativa de garantir a efetivação da gestão democrática nas escolas e do processo democrático e participativo do provimento da gestão escolar, os municípios parecem ainda não terem pautado essa exigência de forma prioritária nas suas agendas políticas sendo possível observar traços patrimonialistas, mesmo com as orientações normativas chancelarem a importância da gestão democrática. Nesse sentido, o papel do MP estadual do Rio de Janeiro é peça chave para sua concretização e é fundamental o acompanhamento permanente das ações do Ministério Público, das regulamentações da gestão democrática e dos processos de seleção de diretores nos municípios do estado do Rio de Janeiro. Ou, então, vamos mais uma vez permitir que interesses privados de toda sorte tornem a defesa da gestão democrática um discurso vazio, transformando-se, como destaca Lima (2014) num slogan, num lugar comum que todos invocam e que hoje atravessa profunda crise.

\section{REFERÊNCIAS}

ARARUAMA, RJ. Lei. n. 1961, de 24 de junho de 2015. Aprova o Plano Municipal de Educação adequado em conformidade com o artigo 162 da Lei Orgânica do Município de Araruama e da Lei Federal, n. 13.005/2014, e dá outras providências.

ARMAÇÃO DE BÚZIOS, RJ. Lei n. 1114, de 30 de junho de 2015. Dispõe sobre aprovar o Plano Municipal de Educação para o Decênio 2015/2025 e dá outras providências.

BRASIL. Lei N. 13.005, de 25 de junho de 2014. Aprova o Plano Nacional de Educação - PNE e dá outras providências. Diário Oficial da União. Brasília: DF, 25 jun. 2014. Disponível em: <http://www.planalto.gov.br/ccivil_03/_Ato20112014/2014/Lei/L13005.htm>. Acesso em 20 out. 2017.

BRASIL. Lei N. 9394, de 20 de dezembro de 1996. Estabelece as Diretrizes e Bases da Educação Nacional. Diário Oficial da União. Brasília: DF, 20 dez. 1996. Disponível em: <http://legis.senado.gov.br/legislacao/ListaTextoIntegral.action?id=75723> Acesso: em 20 out. 2017.

BRASIL. Diretoria de estudos educacionais. Relatório do $1^{\circ}$ Ciclo de Monitoramento das Metas do PNE: Biênio 2014-2016. INEP. DIRED. Brasil: Brasília-DF, 2016.

CABO FRIO, RJ. Lei n. 2.382, de 4 de outubro de 2011 - Consulta para diretores de escolas. 
CABO FRIO, RJ. Lei n. 1853, de 25 de outubro de 2005. Dispõe sobre o processo de consulta para indicação de diretores das unidades de ensino da rede pública municipal de cabo frio, e dá outras providências.

CABO FRIO, RJ. Lei n. 2.644, de $\mathbf{1}^{\circ}$ de julho de 2015. Aprova o Plano de Educação no âmbito do Município de Cabo Frio e dá outras providências.

CACHOEIRAS DE MACACU, RJ. Lei n. 2.056, de 24 de junho de 2015. Aprova o Plano Municipal de Educação e dá outras providências.

CARMO, RJ. Lei n. 1.763, de 23 de junho de 2015. Dispõe sobre a aprovação do PME - Plano Municipal de Educação com vigência nos próximos 10 (dez) anos a contar da publicação desta Lei e dá outras providências.

CARMO, RJ. Lei n. 1852 de 25 de setembro de 2016. Dispõe sobre a instituição da gestão democrática na rede municipal de ensino de Carmo e dá outras providências.

DUQUE DE CAXIAS, RJ. Decreto n. 6543, de 11 de maio de 2015. Dispõe sobre eleições para diretores e vice-diretores das unidades escolares do município de Duque de Caxias. 2015.

IGUABA GRANDE, RJ. Lei n. 1174, de 24 de junho de 2015. Aprova o Plano Municipal de Educação para o Decênio 2015-2025 e dá outras providências.

ITAOCARA, RJ. Lei n. 1.019 de 24 de junho de 2015. Institui o Plano Municipal de Educação na conformidade do artigo241 da Lei Orgânica do Município de Itaocara, Estado do Rio de Janeiro e dá outas providências.

ITAPERUNA, RJ. Lei n. 718, de 23 de junho de 2015. Dispõe sobre a aprovação do Plano Municipal de Educação - PME e dá outas providências.

LAJE DO MURIAÉ, RJ. Lei n. 736, de 29 de junho de 2015. Institui o Plano Municipal de Educação e dá outras providências.

LIMA, Licínio Carlos. A escola como organização e a participação na organização escolar. Braga, Portugal: Universidade do Minho, 1998.

LIMA, Licínio Carlos. Administração escolar: estudos. Porto, Portugal: Porto Editora, 2011.

LIMA, Licínio Carlos. A gestão democrática das escolas: do autogoverno à ascensão de uma pós-democracia gestionária? Educ. Soc., Campinas, v. 35, nº 129, p. 1067-1083, out./dez., 2014.

LIMA, Maria de Fátima Magalhães. Modalidades de escolha e de provimento de diretores escolares: desafios e alternativas para a gestão democrática e o alcance da qualidade da educação. Disponível em:

<http://www.anpae.org.br/iberoamericano2012/Trabalhos/MariaDeFatimaMagalhaesDe Lima_res_int_GT8.pdf>. Acesso em: 20 out. 2017.

RPGE - Revista on line de Política e Gestão Educacional, Araraquara, v. 22, n. esp.1, p. 9-30, mar., 2018. 
LÜCK, Heloisa. Mapeamento de práticas de seleção e capacitação de diretores escolares. São Paulo: Fundação Victor Civita, 2011.

MINISTÉRIO PÚBLICO DO ESTADO DO RIO DE JANEIRO. Cartilha Controle Social na Educação - Gestão democrática e Conselhos. Rio de Janeiro, 2014, p.9-10.

MINISTÉRIO PÚBLICO DO ESTADO DO RIO DE JANEIRO. Portaria de Instauração de inquérito civil n. 2/17 de 12/1/2017.

MINISTÉRIO PÚBLICO DO ESTADO DO RIO DE JANEIRO. Portaria de Instauração de inquérito civil n. 20/2016 de 26/2/2016.

MINISTÉRIO PÚBLICO DO ESTADO DO RIO DE JANEIRO. Recomendação n. 2/17 de 6 de março de 2017.

MINISTÉRIO PÚBLICO DO ESTADO DO RIO DE JANEIRO. Portaria de Instauração de inquérito civil público n. 4/2017 de 6 de fevereiro de 2017.

MINISTÉRIO PÚBLICO DO ESTADO DO RIO DE JANEIRO. Portaria n. 7/2016 de 15 de março de 2016 da Promotoria de Justiça da Comarca de Sumidouro.

MINISTÉRIO PÚBLICO DO ESTADO DO RIO DE JANEIRO. Portaria de Instauração de inquérito civil público n. 3/2016.

MINISTÉRIO PÚBLICO DO ESTADO DO RIO DE JANEIRO. Portaria de Instauração de inquérito civil público N. 2/2016 de 16/2/2016.

MINISTÉRIO PÚBLICO DO ESTADO DO RIO DE JANEIRO. Portaria de Instauração de inquérito civil público s/n de 14 de julho de 2016.

MINISTÉRIO PÚBLICO DO ESTADO DO RIO DE JANEIRO. Portaria de Instauração de inquérito civil público n. 4/2016 de 15 de abril de 2016.

MINISTÉRIO PÚBLICO DO ESTADO DO RIO DE JANEIRO. Portaria de Instauração de inquérito civil público n. 3/2017 de 3 de março de 2017.

MINISTÉRIO PÚBLICO DO ESTADO DO RIO DE JANEIRO. Portaria de Instauração de inquérito civil público n. 24/2016 de 4 de agosto de 2016.

MINISTÉRIO PÚBLICO DO ESTADO DO RIO DE JANEIRO. Portaria de Instauração de inquérito civil público n. 14/2016 de 3 de junho de 2016.

MINISTÉRIO PÚBLICO DO ESTADO DO RIO DE JANEIRO. Portaria de Instauração de inquérito civil público n. 2/2016 de 5 de fevereiro de 2016.

MINISTÉRIO PÚBLICO DO ESTADO DO RIO DE JANEIRO. Recomendação Administrativa N. 1/2016. Portaria de Instauração de inquérito civil público n. 4/2016 de 25 de abril de 2016. 
MINISTÉRIO PÚBLICO DO ESTADO DO RIO DE JANEIRO. Portaria de Instauração de inquérito civil público n. 2/2016 de 19 de fevereiro de 2016.

MINISTÉRIO PÚBLICO DO ESTADO DO RIO DE JANEIRO. Portaria de Instauração de inquérito civil público n. 4/2016 de 16 de março de 2016.

MINISTÉRIO PÚBLICO DO ESTADO DO RIO DE JANEIRO. Portaria de Instauração de inquérito civil público n. 8/2016 de 26 de abril de 2016.

MINISTÉRIO PÚBLICO DO ESTADO DO RIO DE JANEIRO. Portaria de Instauração de inquérito civil público n. 13/2016 de 1 de abril de 2016.

MINISTÉRIO PÚBLICO DO ESTADO DO RIO DE JANEIRO. Portaria de Instauração de inquérito civil público n. 8/2016 de 31 de janeiro de 2016.

MINISTÉRIO PÚBLICO DO ESTADO DO RIO DE JANEIRO. Inquérito civil público n. 2016.00724882 de 1 de julho de 2016.

MINISTÉRIO PÚBLICO DO ESTADO DO RIO DE JANEIRO. Portaria de Instauração de inquérito civil público n. 14/2016 de 30 de abril de 2016.

MINISTÉRIO PÚBLICO DO ESTADO DO RIO DE JANEIRO. Portaria de Instauração de inquérito civil público n. 7/2016 de 21 de março de 2016.

MINISTÉRIO PÚBLICO DO ESTADO DO RIO DE JANEIRO. Portaria de Instauração de inquérito civil público n. 2/2016 de 5 de maio de 2016.

MINISTÉRIO PÚBLICO DO ESTADO DO RIO DE JANEIRO. Recomendação n. 01/2016 e Ação Civil Pública.

MINISTÉRIO PÚBLICO DO ESTADO DO RIO DE JANEIRO. Recomendação n.16/2017 (Ref: IC 01/2016) de 29 de maio de 2017.

MINISTÉRIO PÚBLICO DO ESTADO DO RIO DE JANEIRO. Portaria de Instauração de Inquérito Civil n. 4/16 de 16 de maio de 2016.

MINISTÉRIO PÚBLICO DO ESTADO DO RIO DE JANEIRO. Recomendação N. 17/2015 ref. ao Inquérito Civil n. 233/2015.

MINISTÉRIO PÚBLICO DO ESTADO DO RIO DE JANEIRO. Portaria n. 1/2016 de 25/7/2016.

NATIVIDADE, RJ. Lei n. 726 de 25 de agosto de 2015. Aprova o Plano Municipal de Educação do Município de Natividade, RJ para o Decênio 2015/2025 e dá outras providências.

NATIVIDADE, RJ. Lei n. 796/2016 de 22 de dezembro de 2016. Dispõe sobre a Gestão Democrática do ensino publico municipal e dá outras providências.

RPGE - Revista on line de Política e Gestão Educacional, Araraquara, v. 22, n. esp.1, p. 9-30, mar., 2018. 
NOVA FRIBURGO, RJ. Lei n. 4.395 de 24 de junho de 2015. Institui o Plano Municipal de Educação odo município de Nova Friburgo e dá outras providências.

NOVA FRIBURGO, RJ. Educação democrática: diretores eleitos para unidades municipais são empossados em noite emocionante para a comunidade escolar friburguense. Disponível em: http://novafriburgo.rj.gov.br/2017/02/educacaodemocratica-diretores-eleitos-para-unidades-municipais-sao-empossados-em-noiteemocionante-para-a-comunidade-escolar-friburguense/. Acesso em 21 de junho de 2017.

NOVA FRIBURGO, RJ. Lei. n. 3.929/2011. Estabelece os critérios para nomeação das direções das instituições de ensino mantidas pelo poder público municipal e dá outras providências.

NOVA FRIBURGO, RJ. Lei n. 4.473 de 5 de julho de 2016. Altera o caput e inclui Parágrafo $4^{\circ}$ no artigo $1^{\circ}$ da Lei N. 3.989/2011 ampliando o mandato e garantindo a reeleição aos cargos de diretor e dirigentes de instituições de ensino municipais mantidas elo Poder Público Municipal.

PARAÍBA DO SUL, RJ. Lei n. 3.187 de 28 de maio de 2015. Institui o Plano Municipal de Educação e dá outras providências.

RIO CLARO, RJ. Lei n. 792 de 29 de junho de 2015. Aprova o Plano Municipal de Educação do Município de Rio Claro - RJ e dá outas providências.

RIO DE JANEIRO, RJ, Secretaria Municipal de Educação. Resolução SME N. 20 de 29/9/2017. Dispõe sobre o processo de Seleção de Gestores das Unidades Escolares da Rede Pública do Sistema Municipal de Ensino da Cidade do Rio de Janeiro e dá outras providências.

RODRIGUES, Mariane. Direções Escolares eleitas por consulta às comunidades tomam posse em São Pedro da Aldeia. Disponível em: <http://www.pmspa.rj.gov.br/detalhenoticia.aspx?id=d5fbb56f-91b8-4a4a-bc683b0a390d68a0>. Acesso em: 7 maio 2017.

SÃO JOSÉ DO UBÁ, RJ. Lei n. 427 de 3 de julho de 2015. Aprova o Plano Nacional de Educação de São José de Ubá - RJ e dá outras providências.

SÃO PEDRO DA ALDEIA, RJ. Lei N. 2.606 de 22 de junho de 2015. Aprova o Plano Municipal de Educação - PME.

SAPUCAIA, RJ. Lei 2.593 de 18 de junho de 2015. Aprova o Plano Municipal de Educação para o Decano de 2015 a 2025.

SAQUAREMA, RJ. Lei n. 1.427 de 24 de junho de 2015. Adequa o Plano Municipal de Educação (PME) instituído pela Lei Municipal N. 1053 de 19 de março de 2010 às diretrizes, metas e estratégias previstas no Plano Nacional de Educação (PNE) em conformidade com a Lei Federal n. 13.005 de 25 de junho de 2014. 
SCHWARTZMAN, Simon. Nota sobre o patrimonialismo e a dimensão pública na formação da América Latina contemporânea. 12/10/2006. Disponível em:

$\langle\mathrm{http}$ ://www.schwartzman.org.br/simon/patrimonialismo06.pdf $>$. Acesso em: 30 junho 2017.

SILVEIRA, Adriana Dragone. A busca pela efetividade do direito à educação: análise da atuação de uma Promotoria de Justiça da Infância e Juventude do interior paulista. Educar em Revista, Curitiba, Brasil, n. especial 2, p. 233-250, 2010.

SOARES, Tufi Machado.; TEIXEIRA, Lucia Helena G. Efeito do perfil do diretor na gestão escolar sobre a proficiência do aluno. Estudos em Avaliação Educacional, v. 17, n. 34, maio/ago., 2006.

SOUZA, Ângelo Ricardo de. Explorando e construindo um conceito de gestão escolar democrática, Educação em Revista, Belo Horizonte; v.25, n.03, p. 123-140, dez., 2009.

SUMIDOURO, RJ. Lei. n. 1.116 de 24 de junho de 2015. Institui o Plano Municipal de Educação do município de Sumidouro e dá outras providências.

\section{SUMIDOURO, RJ. Mensagem n. 008/2016 de 30 de maio de 2016 do Prefeito}

Municipal. Encaminha o Anteprojeto de Lei n. 13 de 24 de maio de 2016 que dispõe sobre a gestão democrática do ensino público municipal de Sumidouro/RJ e dá outras providências.

TRÊS RIOS, RJ. Lei n. 4.208 de 22 de junho de 2015. Cria e regulamenta o Plano Municipal de Educação para o período 2015-2025 e dá outras providências.

VALENÇA, RJ. Resolução n. 003/SME/2015, de 3 de novembro de 2015.

VASSOURAS, RJ. Lei n. 2.820 de 7 de julho de 2015. Institui o Plano Municipal de Educação em conformidade com a Lei Orgânica assim como à luz da Lei de Diretrizes e Bases e legislações correlatas e dá outras providências.

VOLTA REDONDA, RJ. Lei n. 5.345 de 30 de maio de 2017. Aprova o Plano Municipal de Educação - PME de Volta Redonda para o decênio 2015-2024.

\section{Como referenciar este artigo}

AMARAL, Daniela Patti do. A regulamentação da gestão democrática e a ação do Ministério Público: desdobramentos no Estado do Rio de Janeiro. Revista on line de Política e Gestão Educacional, Araraquara, v. 22, n. esp.1, p. 9-30, mar., 2018. E-ISSN:15199029.

Submetido em: 04/10/2017

Aprovado em: 14/12/2017

RPGE - Revista on line de Política e Gestão Educacional, Araraquara, v. 22, n. esp.1, p. 9-30, mar., 2018. 